\title{
What do the neuronal memory “engrams” represent?
}

\author{
Andrew C. Papanicolaou \\ Department of Pediatrics, Division of Clinical Neurosciences, \\ University of Tennessee Health Science Center, Memphis \\ apapanic@uthsc.edu
}

\begin{abstract}
The study of the brain mechanisms of mnemonic traces has recently been given substantial impetus by the development of various advanced techniques that can be used in humans and animals. The message of such studies is that the mnemonic traces or engrams of specific experiences are now being identified. This message, however, misrepresents what has actually been accomplished. None of the studies provides evidence that engrams of specific memories such as fear of shock are identified, exclusive of brain activation patterns corresponding to the operations of encoding or consolidation and/or retrieval. This note is meant to rectify that false impression by placing the otherwise impressive findings in their proper perspective: Thus far only the broad outlines of traces of the mnemonic operations combined with those of sensorimotor tasks in animals (and not of episodic experiences in either animals or humans) have been discerned. While this is a major accomplishment, to view it as equivalent to the discovery of engrams of specific experiences is to indulge in hyperbole that is counterproductive to inquiry and undermines the authority of science in the eyes of the general public.
\end{abstract}

Keywords: memory; neuronal encoding; conscious recollections; neuroscience; mnemonic traces.

With the advent of neuroimaging, Lashley's (1950) unsuccessful and longabandoned search for the engrams of implicit memories was resumed, only, this time, with the aim of identifying the neuronal circuits of both implicit and explicit memories, notably memories of personal episodes. There has never been a question as to whether engrams of implicit memories, that is, of sensorimotor habits or automatisms exist in the brain but it also appears to some that there is little doubt that similar engrams representing episodes exist as well. The latter belief was vindicated by Wilder Penfield's reports (e.g. 
Penfield and Perot 1963) that electrical stimulation of the exposed cortex elicits complex episodic memories in the manner that pressing the "play" button on an old tape-recorder may initiate the re-playing of a song. The same belief motivates much of the neuroimaging work with humans and animals cited in a highly informative review (Josselyn et al. 2015). But have engrams of any memories at all and of personal memories in particular ever been isolated as some of the reviewed studies imply and, more importantly, what would be the requirements for accomplishing such a feat?

I wish to propose here that such a feat has yet to be accomplished and to also outline the prerequisites for its possible future accomplishment. Specifically, I will suggest that (a) engrams obtained from animals in the context of sensorimotor learning tasks may not be construed as codes of episodic experiences like the experience of "fear of shock"; (b) that whether found in animals or humans, such mnemonic traces as those discussed in the aforementioned review may not be said to correspond exclusively to the items learned or memorized and (c) that the only indications of item-specific engrams, as exemplified, for instance, in a recent study of Deuker et al. (2013) concern concepts and not episodic experiences; that, in short, the impressions the reader of the relevant literature may form are likely to be misleading and, to that degree, counterproductive to the conduct of further inquiry.

There are several conjectures as to the nature of engrams of all types of memories whether implicit or explicit, that is episodic (i.e. memories of personal experiences of events) and semantic, such as experiences of the meaning of concepts. Most are based on the notion of cell-assemblies (Hebb 1949) whereby separate circuits of interconnected neurons code for the names of concepts, for the content of both, concepts and events, and for each of the countless sensorimotor habits. It is also universally accepted that consolidation of all types of memories requires activation (possibly repeated) of special purpose brain mechanisms or networks (that is networks that handle all experiences) that are believed to reside in the limbic cortex and parts of the neocortex and that recognition of a concept or the re-experiencing of an episode, involves the activation of retrieval mechanisms (either the same or different from those that mediate consolidation) which, in turn, re-activate the dormant itemspecific engram. As the authors of the review cited above state "...an engram exists beyond the operations and processes required to form and recover it" (Josselyn et al. 2015: 521). These notions, however, give rise the technical problem of how to image separately the activation of the mechanisms of retrieval and consolidation from that corresponding to the mnemonic trace of specific episodes.

Moreover, relevant studies, to the degree that involve animals, (e.g. Davidson et al. 2009) could never support the claim that the engrams of explicit episodic experiences (like fear) have been identified, for a very simple reason: the ac- 
tivity recorded during encoding of the episode from an animals' brain as well as its spontaneous re-emergence later (purportedly during the stage of consolidation) corresponds to the entire learning task which entails specific sensory and motor events plus the activation of the operation-specific networks (of consolidation and of spontaneous retrieval). It is also completely conjectural whether the engrams correspond to a subjective experience in animals similar to that of the human fear. Therefore, the impression that recent neuroimaging studies have identified engrams of episodes (that is, once again, engrams of explicit experiences like fear) is factually incorrect.

Equally problematic would be interpreting the results of the human studies purportedly furnishing evidence for episodic memory engrams. Such studies involve measurements of the hemodynamic response patterns of human subjects during encoding of episodes and computation of their similarity to those emerging spontaneously later, either during sleep (e.g. Maquet et al. 2000; Peigneux et al. 2004) or during a post-encoding awake period (e.g. Peigneux et al. 2006; Tambini et al. 2010; Staresina et al. 2013). Assuming replicability of the reported findings which is not readily obtained with measurements and calculations of the type involved in such studies (see e.g. Papanicolaou 2015) one would still be unjustified concluding that the patterns in question are those of the particular episodic engrams rather than those corresponding to both the activation of the consolidation and spontaneous retrieval mechanisms, common to all experiences, plus, possibly, those corresponding to the specific episodic trace being established. Yet some authors do make such unjustifiable claims as ".... we can now study the dynamics of memory processes of specific experiences...” (e.g. Staresina et al. 2013: 21159)

There is however, a particular genre of studies exemplified, as previously mentioned, by that of Deuker and his associates (Deuker et al. 2013) that could enable, in principle, the identification of individual mnemonic traces. However, none of those have reported the identification of the engrams of episodic experiences but only those of concepts, which is an altogether different matter: Episodes, in order to be experienced as meaningful events, presuppose knowledge of the nature of each perceived, or imagined, or thought of, element that constitutes them; knowledge, for instance, of what the percept "table" is and what "eating" means, in order for one to experience the episode of "eating out with friends" as a meaningful event. These constituents, that are many and varied even in very simple episodes, are semantic memories, that is, concepts.

Concepts come in two basic varieties: abstract and concrete. Both types consist of the words that name them and of their semantic content. In the case of concrete concepts, the content is, or can be, a sensory (e.g. visual) mental image. In the case of the abstract concepts the content is harder to specify. On one view, the one forcefully advanced by Berkeley—see especially his "Intro- 
duction" (Berkeley 1710/1881) - the content of abstract concepts is but a collection of concrete, that is, sensory or pictorial images sharing some cardinal attributes and the words that name them. Whether this view is correct or not is of little importance here since the functional neuroimaging literature concerns engrams of concrete concepts of, mostly, visual objects.

But assuming, once again, that the reported results of these studies (e.g. Haxby et al. 2001; Cox and Savoy 2003; Hoshi et al. 2005; Kay et al. 2008; Mitchell et al. 2008; Naselaris et al. 2009; Just et al. 2010) usually involving the technique of multivariate pattern analysis (MVPA) are replicable and valid, they concern not episodic memories but individual concepts. And, unless and until the first evidence of isolation of episode-specific engrams appear, it is not at all advancing the proper conduct of inquiry if scientists entertain themselves and the public with tales of possible yet still unrequited wishes, presented in the guise of fact.

\section{References}

Berkeley, G. 1710/1881. A treatise concerning the principles of human knowledge. JB Lippincott \& Company.

Cox, D.D., Savoy, R.L. 2003. Functional magnetic resonance imaging (fMRI) "brain reading": detecting and classifying distributed patterns of fMRI activity in human visual cortex. Neuroimage, 19: 261-270.

Davidson, T.J., Kloosterman, F., Wilson, M.A. 2009. Hippocampal replay of extended experience. Neuron, 63: 497-507.

Deuker, L., Olligs, J., Fell, J., Kranz, T.A., Mormann, F., Montag, C., Reuter, M., Elger, C.E., Axmacher, N. 2013. Memory consolidation by replay of stimulus-specific neural activity. J Neurosci, 33: 19373-19383.

Haxby, J.V., Gobbini, M.I., Furey, M.L., Ishai, A., Schouten, J.L., Pietrini, P. 2001. Distributed and overlapping representations of faces and objects in ventral temporal cortex. Science, 293: 2425-2430.

Hebb, D.O. 1949. The organization of behavior: A neuropsychological theory: New York: Wiley.

Hoshi, E., Tremblay, L., Feger, J., Carras, P.L., Strick, P.L. 2005. The cerebellum communicates with the basal ganglia. Nat Neurosci, 8: 1491-1493.

Josselyn, S.A., Kohler, S., Frankland, P.W. 2015. Finding the engram. Nat Rev Neurosci, 16: 521-534.

Just, M.A., Cherkassky, V.L., Aryal, S., Mitchell, T.M. 2010. A neurosemantic theory of concrete noun representation based on the underlying brain codes. PloS one, 5: e8622. 
Kay, K.N., Naselaris, T., Prenger, R.J., Gallant, J.L. 2008. Identifying natural images from human brain activity. Nature, 452: 352-355.

Lashley, K.S. 1950. In search of the engram. In: In Society of experimental biology symposium no. 4: Physiological mechanisms in animal behaviour. Cambridge, England: Cambridge University Press.

Maquet, P., Laureys, S., Peigneux, P., Fuchs, S., Petiau, C., Phillips, C., Aerts J., Del Fiore, G., Degueldre, C., Meulemans, T. 2000. Experience-dependent changes in cerebral activation during human REM sleep. Nat Neurosci, 3: 831-836.

Mitchell, T.M., Shinkareva, S.V., Carlson, A., Chang, K-M., Malave, V.L., Mason, R.A., Just, M.A. 2008. Predicting human brain activity associated with the meanings of nouns. Science, 320: 1191-1195.

Naselaris, T., Prenger, R.J., Kay, K.N., Oliver, M., Gallant, J.L. 2009. Bayesian reconstruction of natural images from human brain activity. Neuron, 63: 902-915.

Papanicolaou, A.C. 2015. The Default Mode and Other Resting State Networks. In: Oxford Handbooks Online. Oxford University Press.

Peigneux, P., Orban, P., Balteau, E., Degueldre, C., Luxen, A., Laureys, S., Maquet, P. 2006. Offline persistence of memory-related cerebral activity during active wakefulness. PLoS Biol, 4: 647.

Peigneux, P., Laureys, S., Fuchs, S., Collette, F., Perrin, F., Reggers, J., Phillips, C., Degueldre, C., Del Fiore, G., Aerts, J. 2004. Are spatial memories strengthened in the human hippocampus during slow wave sleep? Neuron, 44: 535-545.

Penfield, W., Perot, P. 1963. The brain's record of auditory and visual experience. A final summary and discussion. Brain, 86: 595-696.

Staresina, B.P., Alink, A., Kriegeskorte, N., Henson, R.N. 2013. Awake reactivation predicts memory in humans. Proc Natl Acad Sci USA, 110: 21159-21164.

Tambini, A., Ketz, N., Davachi, L. 2010. Enhanced brain correlations during rest are related to memory for recent experiences. Neuron, 65: 280-290. 